\title{
EVOLUTIONARY IMPLICATIONS OF A HIGH SELFING RATE IN THE FRESHWATER SNAIL LYMNAEA TRUNCATULA
}

\author{
S. Trouvé, ${ }^{1,2}$ L. Degen, ${ }^{1}$ F. Renaud ${ }^{3}$ And J. Goudet ${ }^{1}$ \\ ${ }^{1}$ Département d'Ecologie et Evolution, Bâtiment Biologie, Université de Lausanne, 1015 Lausanne, Switzerland \\ ${ }^{2}$ E-mail: Sandrine.Trouve@ie-zea.unil.ch \\ ${ }^{3}$ Centre d'Etude sur le Polymorphisme des Micro-Organismes, UMR 9926 IRD CNRS, Centre IRD Montpellier, \\ 911 avenue Agropolis, 34032 Montpellier Cedex 1, France
}

\begin{abstract}
Self-compatible hermaphroditic organisms that mix self-fertilization and outcrossing are of great interest for investigating the evolution of mating systems. We investigate the evolution of selfing in Lymnaea truncatula, a self-compatible hermaphroditic freshwater snail. We first analyze the consequences of selfing in terms of genetic variability within and among populations and then investigate how these consequences along with the species ecology (harshness of the habitat and parasitism) might govern the evolution of selfing. Snails from 13 localities (classified as temporary or permanent depending on their water availability) were sampled in western Switzerland and genotyped for seven microsatellite loci. $F_{\text {IS }}$ (estimated on adults) and progeny array analyses (on hatchlings) provided similar selfing rate estimates of $80 \%$. Populations presented a low polymorphism and were highly differentiated $\left(F_{\mathrm{ST}}=0.58\right)$. Although the reproductive assurance hypothesis would predict higher selfing rate in temporary populations, no difference in selfing level was observed between temporary and permanent populations. However, allelic richness and gene diversity declined in temporary habitats, presumably reflecting drift. Infection levels varied but were not simply related to either estimated population selfing rate or to differences in heterozygosity. These findings and the similar selfing rates estimated for hatchlings and adults suggest that within-population inbreeding depression is low in $L$. truncatula.
\end{abstract}

Key words._Gastropoda, habitat quality, inbreeding depression, mating system, microsatellites, parasitism, selfing.

Received August 2, 2002. Accepted April 16, 2003.

The maintenance of biparental reproduction, with its associated costs and benefits, is a standing problem in evolutionary biology (Darwin 1876; Ghiselin 1974; Maynard Smith 1978) and substantial debates continue regarding most aspects of mating system evolution (e.g., Hurst and Peck 1996; Jokela et al. 1997; Ayala 1998; Agrawal and Lively 2001; Herlihy and Eckert 2002; Victoir and Dujardin 2002). Self-compatible hermaphrodite organisms offer ideal models to examine the evolution of two different mating systems: outcrossing and selfing.

The evolution of outcrossing versus selfing can be viewed as a conflict between two genetic phenomena: the cost of outcrossing and inbreeding depression (Maynard Smith 1978; Charlesworth 1980). The cost of outcrossing corresponds to a gene transmission advantage of selfing (Fisher 1941) and derives from a 3:2 excess of successful gametes for selfers compared to outcrossers. The second, inbreeding depression, is a decrease in fitness of selfed progenies when compared to those that are outcrossed (Charlesworth and Charlesworth 1987, 1990). The available data concerning the genetic basis of inbreeding depression suggest that it can be due to recessive or partly recessive deleterious alleles that are maintained in populations by a mutation-selection balance (dominance hypothesis) or to superiority of heterozygotes over homozygotes at loci determining fitness (overdominance). However, overdominance seems of less importance (Charlesworth and Charlesworth 1990; Crow 1999a,b). Theoretical models show that if the inbreeding depression is less than 0.5 , a gene causing self-fertilization will spread in a population, and selfing will be favored. Whereas if the inbreeding depression is greater than 0.5, outcrossing will be favored (Maynard Smith 1978; Charlesworth 1980; but see Uyenoyama et al. 1993). This simple rule, based on genetic factors, turns out to be complicated by both genetic factors (e.g., associations that develop between alleles at different loci) and ecological factors (e.g., reproductive assurance). The relative importance of these factors in the evolution of mating systems has been extensively studied in plants. In animals, however, where hermaphroditism occurs in most metazoan groups, information has just started to accumulate (in ascidians: Bishop and Ryland 1993; Cohen 1996; platyhelminthes: Trouvé et al. 1996, 1999a,b; snails: Jarne and Delay 1990; CoutellecVreto et al. 1997; Städler and Jarne 1997), and much more work remains to be done.

This is the context of our work, which focuses on the hermaphroditic freshwater snail Lymnaea truncatula. In this species, it has long been known that an isolated individual can produce fertile eggs (Roberts 1950; Kendall 1953). We evaluate in this study factors involved in the evolution of selfing and we consider more particularly the effect of inbreeding depression, the temporality of the habitat, and parasitism.

The production of inbred individuals resulting from selfing might constitute a major disadvantage for the evolution of selfing in L. truncatula if these individuals have lower fitness. The estimation of inbreeding depression involves either comparisons of viability and fecundity between individuals of differing inbreeding levels (for review see Keller and Waller 2002), or inferences based on estimated changes in homozygosity along the life cycle (Ritland 1990). This later method will be used in this study, and it has the advantage of being able to measure the inbreeding depression directly in the field.

Population size and metapopulation dynamic may also affect the evolution of mating system (Tomlinson 1966; Pannell and Barrett 1998, 2001), including levels of inbreeding de- 
pression and genetic load (Kirkpatrick and Jarne 2000). Lymnaea truncatula is found in small ponds, small streams, irrigation ditches, wet or swampy pastures, or even in "any depression in the ground which will accumulate and store water' (Smith 1981), such as hoof tracks of cattle. Therefore, individuals inhabit temporary as well as permanent habitats. During harsh periods, when nonpermanent ponds become dry or frozen, populations decrease in size and might even go extinct. The survival of individuals depends on numerous critical parameters such as meteorological factors, soil type, and position of shell aperture (Kendall 1949). The nonpermanency of the habitats should have three main consequences. First, the frequent reduction in population size associated with the transience of the habitats should favor selfing, because this mating system guarantees gene transmission to the next generation when finding a mate is uncertain. Second, because random sampling of gametes affects subsequent gene frequencies, reduced population sizes should decrease the level of genetic diversity through loss of alleles and heterozygosity (Wright 1969; Bonnell and Selander 1974; Nei et al. 1975; Leberg 1992). Thus, populations of L. truncatula from temporary habitats should have a reduced genetic polymorphism compared to populations from permanent ones. Third, population dynamics should also modify the partitioning of genetic variation among local populations (Slatkin 1977; Whitlock and McCauley 1990; Giles and Goudet 1997). Fluctuations in population size (and extinctions) in temporary habitats strongly reduce the effective size and represent a source of genetic drift. In this context, we predict that differentiation among temporary populations of L. truncatula should be greater than among permanent ones.

Lymnaea truncatula constitutes the main intermediate host in transmission of a number of digenetic parasites (Platyhelminthes), known to be extremely harmful to the snail (Malek 1980). In the struggle against pathogens, homozygosity and reduced variability resulting from selfing might constitute major disadvantages. To understand how parasitism might constitute a major factor preventing the evolution of self-fertilization, we consider two common models of resistance to parasites. First, resistance might be controlled by a few genes and host-parasite interactions could then be considered from the point of view of particular genetic models (Flor 1956; Frank 1993, 1994; Otto and Michalakis 1998; Agrawal and Lively 2001). Under the matching-allele model, for instance, sexuality has classically been viewed as advantageous in the struggle against parasites. In sexual hosts, recombination confers an advantage because it generates new genetic combinations capable of resisting attacks by locally adapted parasites (Red Queen hypothesis: Van Valen 1973; Jaenike 1978; Hamilton et al. 1990). Biparental reproduction should therefore be more common in infected populations (but see Ladle et al. 1993; Lively and Howard 1994; Agrawal and Lively 2001). Second, resistance to parasites can be seen as a trait related to fitness, and its relation with heterozygosity can be investigated. Under this paradigm, inbred individuals should have a lower fitness due to the expression of mildly deleterious alleles and/or the nonexpression of overdominance (Charlesworth and Charlesworth 1987, 1990). Hosts with heterozygous genotypes would better resist infection than homozygous genotypes. In this context, when hosts and parasites originate from the same population, we expect inbred individuals to be preferentially infected (Jarne and Théron 2001).

The purpose of this study is to accurately estimate the selfing rate (selfing has been reported but not quantified in this species), to analyze the consequences of this mating system in terms of genetic variability within and among populations, and to investigate how selection and levels of inbreeding may favor the evolution of selfing versus outcrossing in combination with this species' ecology.

\section{Materials And Methods}

Lymnaea truncatula (Gastropod, Lymnaeidae) is a diploid hermaphroditic freshwater snail. Dispersal in snails occurs over small distances via animal movements and at larger distances via movements of birds, water flow, or human activities (Malone 1965; Purchon 1968; Boag 1986; Bilton et al. 2001). Lymnaea truncatula constitutes the first intermediate host essential to the accomplishment of the life cycle of many digenetic parasites (Malek 1980). Most digeneans (Platyhelminthes) affect the fitness of the first intermediate host by inducing their castration and even sometimes premature death (Malek 1980; Sorensen and Minchella 1998).

Sampling of adult snails took place in Switzerland and ranged from the Jura to the Lemanic plain (Fig. 1). Thirteen populations separated by about $25 \mathrm{~m}$ to $120 \mathrm{~km}$ have been sampled. About 100 snails from each population were collected in autumn 1998, except for the population of Lac de Bret, which was collected in spring 1999. Fall and spring are favorable to investigate the mating system because they correspond to reproductive seasons clearly identified in this species (Rondelaud and Mage 1992 and references therein). Snails were brought back to the laboratory between layers of wet paper in small boxes.

Snails were found in two types of habitats differing by water availability: permanent and temporary habitats. Permanent habitats are ponds subsisting the whole year, and temporary habitats are ponds that dry up once or numerous times per year. Snails were sampled in five permanent and eight temporary populations (Table 1). In each site an area of about $15 \mathrm{~m}^{2}$ was sampled to minimize the likelihood of sampling a unique family and avoid Wahlund effects.

To estimate the proportion of individuals infected in each population, snails were dissected under a binocular microscope and screened for the presence of digenetic parasites. Tissues from the foot of 569 adult parasitized or healthy snails were genotyped at seven microsatellite loci (loci 16 , 20, 21, 24, 29, 36 and 37: Trouvé et al. 2000).

\section{Genetic Data Analyses}

Allelic count and richness (a measure of allele number independent of sample size; see El Mousadik and Petit 1996; Petit et al. 1998), as well as observed and expected heterozygosities within samples (following Nei 1987) were estimated with the program FSTAT version 2.9.3 (Goudet 2001), which also calculates Weir and Cockerham (1984) estimators of $F$-statistics $\left(f\right.$ estimates $F_{\text {IS }}, \theta$ estimates $F_{\mathrm{ST}}$ ). Randomization procedures were used to test for departure from panmixia and for differentiation among populations (Goudet et 


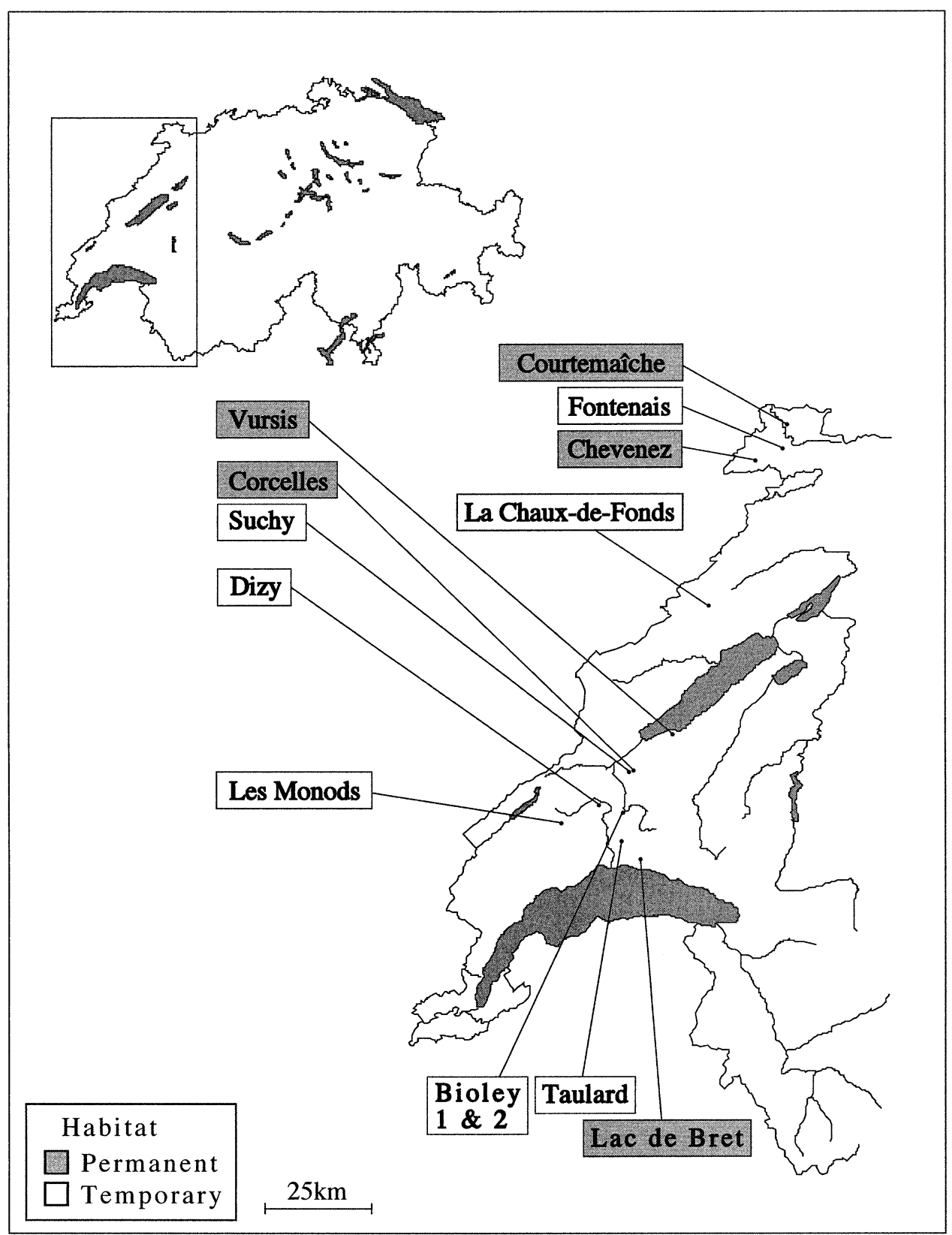

FIG. 1. Geographic localities of the populations studied in Switzerland.

al. 1996; Petit et al. 2001) and were performed with FSTAT. To guard against false significant results due to multiple testing, a Bonferroni correction (Rice 1989) was applied to tests on each sample and pairs of populations. To test for isolation by distance we followed Rousset (1997), who described the appropriate transformations for pairwise $F_{\mathrm{ST}}$ and geographical distances for such a test. For $F_{\mathrm{ST}}$, the transformation is $F_{\mathrm{ST}} /\left(1-F_{\mathrm{ST}}\right)$. Because the habitat colonized by L. truncatula is not-unidimensional, the significance of the relationship was tested on log-transformed geographic distances by mean of a Mantel test (Manly 1997). The matrix of geographic distances corresponded to the straight-line distances measured on a map because the sampling sites are not connected by river basins or systems of drains.
Statistical independence among loci was assessed using the genotypic disequilibrium test of FSTAT version 2.9.3 (Goudet 2001). For each pair of loci in each sample, the table of genotypic association is obtained. The statistic used to test the tables is the log-likelihood ratio $G$-statistic. Only individuals typed at both loci enter the table. The $P$-value of the test is obtained as follows. Genotypes at the two loci are associated at random within samples a number of times (5000) and the $G$-statistic is recalculated on the randomized dataset. The $P$-value is estimated as the proportion of $G$ statistics from randomized datasets that are larger or equal to the observed. An overall sample statistic is obtained by summing the $G$-statistics over all samples. The overall test is obtained by comparing this overall $G$-statistic with that 
TABLE 1. Ecological characteristics of populations. T, temporary habitat; P, permanent habitat; $N$, number of individuals dissected; $\%$ of infection, percentage of snails parasitized by digenetic parasites.

\begin{tabular}{lccc}
\hline \hline \multicolumn{1}{c}{ Populations } & Habitat & $N$ & $\begin{array}{c}\text { \% of } \\
\text { infection }\end{array}$ \\
\hline Bioley 1 & $\mathrm{T}$ & 65 & 0.00 \\
Bioley 2 & $\mathrm{T}$ & 51 & 0.00 \\
Chaux-de-Fonds & $\mathrm{T}$ & 43 & 0.00 \\
Dizy & $\mathrm{T}$ & 75 & 36.00 \\
Fontenais & $\mathrm{T}$ & 116 & 0.00 \\
Monods & $\mathrm{T}$ & 110 & 17.27 \\
Suchy & $\mathrm{T}$ & 148 & 46.62 \\
Taulard & $\mathrm{T}$ & 120 & 15.83 \\
Chevenez & $\mathrm{P}$ & 124 & 37.90 \\
Corcelles & $\mathrm{P}$ & 105 & 25.71 \\
Courtemaîche & $\mathrm{P}$ & 136 & 0.00 \\
Lac de Bret & $\mathrm{P}$ & 97 & 1.03 \\
Vursis & $\mathrm{P}$ & 126 & 7.94 \\
\hline
\end{tabular}

obtained from randomized tables (randomization occurring only within samples).

\section{Mating System}

Two approaches (indirect and direct) were used to investigate the reproductive system exhibited by this species. Assuming that inbreeding only results from self-fertilization, a selfing rate has been indirectly estimated using the classical equation $F_{\text {IS }}=s /(2-s)$ (Hartl and Clark 1997). This estimation is based on adult individuals and assumes the population to be at equilibrium. It furnishes an average selfing rate over several generations. However, if biparental inbreeding is occurring, selfing estimated from this formula will be overestimated; if selection operates against homozygous genotypes, selfing will be underestimated.

To account for these potential biases, we also took the direct approach of progeny array analysis (Ritland and Jain 1981), which provides a single-generation estimate. This method compares the maternal genotype with those of its offspring born in the laboratory but issued from mating that occurred in natura (snails store sperm and use it for several months after copulation; Wethington and Dillon 1991; for a review see Jarne et al. 1993; Dillon 2000). After field collection, snails were rapidly isolated in the laboratory in plastic goblets filled with water of Lake Leman (sometimes misnamed Lake Geneva), maintained at a constant temperature of $17^{\circ} \mathrm{C}$ and fed ad libitum with defrosted lettuce. These individuals (also used in the analysis of population structure) constituted the parents for the progeny array. Snails were allowed to lay eggs during three weeks, and the order of egg capsule appearance was noted. The hatching rate was high, about $95 \%$, which confirms previous work reporting little or no mortality until hatching (Kendall 1949). As soon as the eggs hatched, juveniles were collected and frozen prior to genetic analyses. Twenty-three to 44 juveniles, originating from four to seven families, were analyzed in each of six populations. The choice of the populations for the progeny array analyses includes the whole range of the observed $F_{\text {IS }}$ and temporary as well as permanent populations. We estimated single and multilocus outcrossing rates with a maxi- mum-likelihood procedure using the MLTR program (Ritland 1986), which calculates a selfing rate using the allelic frequencies in the respective populations. To obtain a good estimation of the allelic frequencies, and thus of the selfing rate, the program was run with all the genotyped individuals for each population whether we analyzed their offspring or not. Standard deviations of the selfing rate estimates were obtained from 500 bootstraps. MLTR compares the singlelocus $\left(s_{\mathrm{s}}\right)$ and multilocus selfing rate $\left(s_{\mathrm{m}}\right)$ to discriminate the part of inbreeding due to biparental inbreeding to the one due to selfing (Ritland and Jain 1981; Ritland 1986). The method of Waller and Knight (1989), which is based on genotypic correlations between male and female gametes, was also used to estimate biparental inbreeding in those progeny arrays that include outcrossed offspring. Furthermore, we note here that a lower selfing rate estimated on adult (with the $F_{\text {IS }}$-based approach) than on hatchling (with progeny array analysis) would indicate inbreeding depression (Ritland 1990).

\section{Harshness of the Habitat}

Because temporary populations are likely to undergo frequent fluctuations in population size, one might expect that they would show higher selfing rates (and therefore higher $F_{\text {IS }}$ ) compared to permanent ones. We also expect temporary ponds to exhibit a lower allelic richness and genetic diversity and to be more differentiated among themselves than permanent ones. To test for this, we estimated for the two groups (permanent vs. temporary) $F_{\text {IS }}$, allelic richness $(R s)$, gene diversity $\left(H_{\mathrm{e}}\right)$, and $F_{\mathrm{ST}}$ and took, for each statistic ( $F_{\mathrm{IS}}, R s$, $\left.H_{\mathrm{e}}, F_{\mathrm{ST}}\right)$, the difference among the two groups. Under the null hypothesis of no difference between the two groups, the observed difference in these four statistics should not be greater than what is expected by randomly allocating samples to the two types of habitat (keeping the number of samples in each habitat constant); 5000 randomizations were carried out. The alternative hypothesis is that permanent habitats have a higher allelic richness and gene diversity, but a lower $F_{\text {IS }}$ and $F_{\text {ST }}$ than temporary ones. The probability was estimated as the proportion of cases in which the difference in allelic richness, gene diversity, $F_{\text {IS }}$, or $F_{\text {ST }}$ from randomized samples was larger or equal to the observed.

\section{Parasitism}

Because pathogens are important selective agents, we analyzed the relation between selfing rate and parasitic level among populations with a Spearman rank correlation. Additionally, in the presence of parasites, small and isolated populations might be more susceptible to infection if they have lost genetic variation or accumulated more deleterious mutations. Spearman rank correlation was therefore applied to test whether isolated populations present higher prevalence of infection. The degree of isolation of each population was estimated by its average pairwise $F_{\mathrm{ST}}$ with all other populations.

Due to reduced fitness, inbred genotypes might be preferentially infected by parasites. We therefore compared the observed heterozygosity of healthy and infected snails in each population to test whether infected snails had lower hetero- 
zygosity. Each pond was split in two groups of parasitized and nonparasitized individuals. The heterozygosity of infected and healthy groups was then compared within each population. To test for differences in heterozygosity between these groups, we used a randomization test included in FSTAT version 2.9.3 (Goudet 2001). We randomly assigned a parasitized status to each individual in proportion to the number of parasitized individuals in each sample. We then compared the difference in heterozygosity between the pseudo-parasitized and pseudo-healthy groups in 10,000 sample runs. The probability of our null hypothesis was estimated as the proportion of randomized datasets that gave a difference in heterozygosity larger or equal to the observed.

\section{RESUlts}

\section{Within-Population Variability}

The total number of alleles observed per locus across the sampling area ranged from four (locus 37) to nine (loci 36, 16). Two populations, Dizy and La Chaux-de-Fonds, are monomorphic for the seven microsatellite loci (Table 2), but the genotype in Dizy is different from that in La Chaux-deFonds. The mean number of alleles per microsatellite locus per population varied from 1.0 for Dizy and La Chaux-deFonds to 3.43 for Lac de Bret (Table 2). The mean gene diversity is low for microsatellite markers, ranging from 0.0 in Dizy and La Chaux-de-Fonds to 0.52 in Bioley 2. Additionally, the mean observed heterozygosity is very low $\left(H_{\mathrm{o}}\right.$ $=0.06$ ).

\section{Mating System}

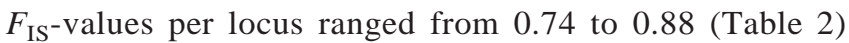
and show highly significant deviations from Hardy-Weinberg expectations $\left(P<0.0002\right.$ for each locus). $F_{\text {IS }}$-based estimates of selfing are strikingly high. Selfing rates range from $42 \%$ to $98 \%$; eight of 11 populations exhibit a selfing rate higher than $80 \%$. The MLTR method of Ritland (1986) provided similar estimates: the population selfing rates estimated as an average of the individual rate range from $46 \%$ to $100 \%$ (Table 3). Outcrossing only occurred in three of the 25 families (with more than four offspring) and 22 of these 25 appear to self-fertilize at $100 \%$ (Table 3 ). In each family where outcrossing occurred, only one outcross father was detected. Egg capsules laid later do not show an increased selfing rate and still indicated the occurrence of outcrossing events (data not shown). Differences between single and multilocus estimates of outcrossing rates and estimates of biparental inbreeding (Waller and Knight 1989) are small in five of the six populations (Table 3). The Corcelles population, however, exhibits higher biparental inbreeding (0.26). The selfing rates estimated on hatchlings (with the MLTR method) and on adults (with the $F_{\text {IS }}$-based method) are similar, suggesting little or no inbreeding depression for survival between hatching and adulthood.

\section{Genotypic Disequilibrium}

Of the 21 pairs of loci analyzed, 11 pairs show significant linkage disequilibrium, although never in more than three populations. Additionally, disequilibrium varies widely among populations. In Chevenez nearly half the pairs of loci are in disequilibrium, whereas in Corcelles no disequilibrium was detected.

\section{Spatial Structure}

The genetic differentiation among populations is highly significant $(P=0.001)$ with a mean $\theta$-value (the estimator of population genetic differentiation following Weir and Cockerham 1984) of 0.58. The individual loci estimates of $F_{\text {ST }}$ were consistent across all seven loci (Table 2). Pairwise $\theta$-values ranged from 0.4 (e.g., between Courtemaiche and Monods or between Bioley 2 and Lac de Bret) to 1.0 (between Dizy and La Chaux-de-Fonds or between Bioley 1 and Dizy). All the pairwise comparisons are strongly significant after Bonferroni correction. Even at a small scale, genetic differentiation is high. In Bioley, two samples separated by $25 \mathrm{~m}$ are significantly differentiated $\left(F_{\mathrm{ST}}=0.5, G\right.$-test: $P=$ $0.0001)$. No isolation by distance was detected, and geographic distance explains none of the variability in genetic distance $\left(r^{2}=0.0029, P=0.613\right)$.

\section{Harshness of the Habitat}

Although $F_{\text {IS }}$ from temporary habitats is not significantly higher than that from permanent ones $\left(F_{\text {IS }}[\right.$ temp $]=0.83 \mathrm{vs}$. $F_{\text {IS }}[$ perm $\left.]=0.77, P=0.38\right)$, permanent habitats do exhibit a significantly higher allelic richness $\left(r_{\mathrm{s}}[\right.$ perm $]=2.62 \mathrm{vs}$. $r_{\mathrm{s}}$ [temp $\left.]=1.86, P=0.03\right)$ and gene diversity $(H \mathrm{e}[$ perm $]=$ 0.40 vs. $H \mathrm{e}[$ temp] $=0.25, P=0.03) . F_{\mathrm{ST}}$ among temporary samples is slightly but not significantly higher than among permanent ones $\left(F_{\mathrm{ST}}[\right.$ temp $]=0.65$ vs. $F_{\mathrm{ST}}[$ perm $]=0.51, P$ $=0.11)$.

\section{Parasitism}

Infection levels vary drastically among sites, ranging from $0 \%$ in Fontenais, Courtemaiche, la Chaux-de-Fonds, and Bioley to $47 \%$ in Suchy (Table 1). Within populations, infected individuals do not exhibit significantly lower heterozygosity than healthy individuals $\left(H_{\mathrm{o}}\right.$ [parasitized] $=0.06 \mathrm{vs}$. $H_{\mathrm{o}}[$ healthy] $=0.074, P=0.19)$. Among populations, infection increases nonsignificantly with the selfing rate $\left(r_{\mathrm{s}}=0.47\right.$, $P=0.13)$ and shows no relation to the degree of population isolation $\left(r_{\mathrm{s}}=-0.14, P=0.64\right)$.

\section{Discussion}

In this work, we have demonstrated that L. truncatula is a preferential selfer, with a low genetic diversity within and high differentiation between populations. The lack of difference in the selfing rate estimates obtained from hatchlings and adults implies similar survival to adulthood of inbred and outcrossed individuals. We also found that parasites do not seem to preferentially target the more inbred genotypes. These two observations suggest that inbreeding depression measured locally is low or absent in this species and support the prediction of low inbreeding depression in preferential selfers (Lande and Schemske 1985; Charlesworth and Charlesworth 1987). Before discussing how inbreeding depression might affect the evolution of mating system in this species, we comment on our findings on genetic variability and mating 
TABLE 2. Genetic characteristics for each population and locus. Number of alleles $(\mathrm{Na})$, gene diversity $\left(H_{\mathrm{e}}\right)$, and $F_{\text {IS }}$ are estimates per locus and per population, as well as averages over loci for each population and over populations for each locus. Means and standard errors of $F_{\text {IS }}$ and $F_{\text {ST }}$ per locus were obtained through jackknifing. $N$ is the number of individuals genotyped and an asterisk indicates significance for departure from Hardy-Weinberg proportions $\left(F_{\text {IS }}\right)$ or for population differentiation $\left(F_{\text {ST }}\right)$ after sequential Bonferroni test. Standard deviations of $\mathrm{Na}$ and $H_{\mathrm{e}}$ are given in parentheses.

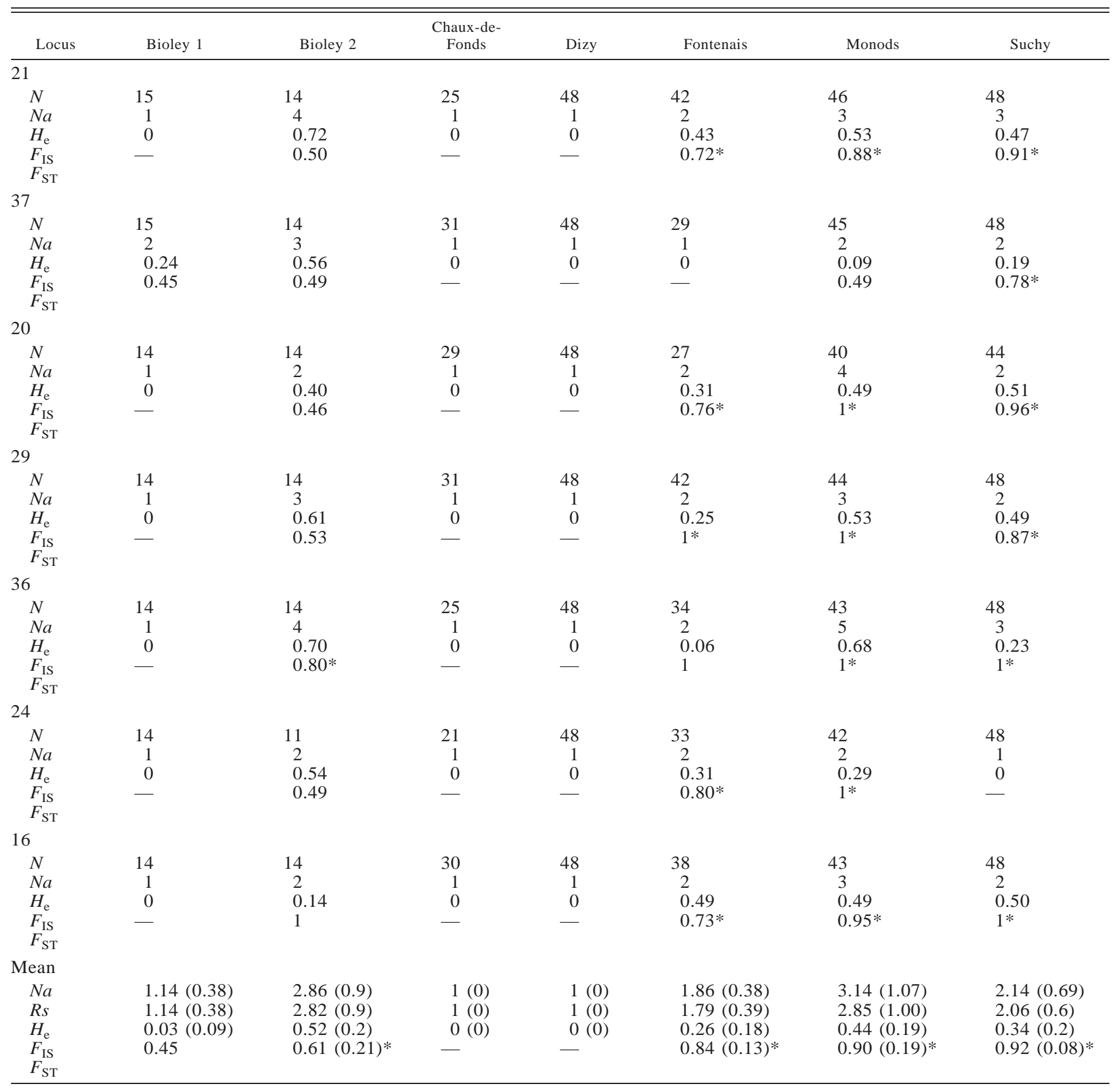

system in L. truncatula. We then turn to the effect of population dynamic and parasitism on mating system and population genetic parameters.

\section{Within-Population Variability}

Despite the high mutation rates characteristic of microsatellite loci (Jarne and Lagoda 1996), the genetic variability detected in our study was globally low. Surprisingly, no polymorphism was observed in two populations, Dizy and La Chaux-de-Fonds. This means that for the seven microsatellite loci investigated, the 48 and 25 individuals screened in the respective populations appeared as clones. Because caution was taken to sample several families in each population, this result cannot be attributed to a sampling artifact. We did find some genetic differences, unlike Meunier et al. (2001), who 
TABLE 2. Extended.

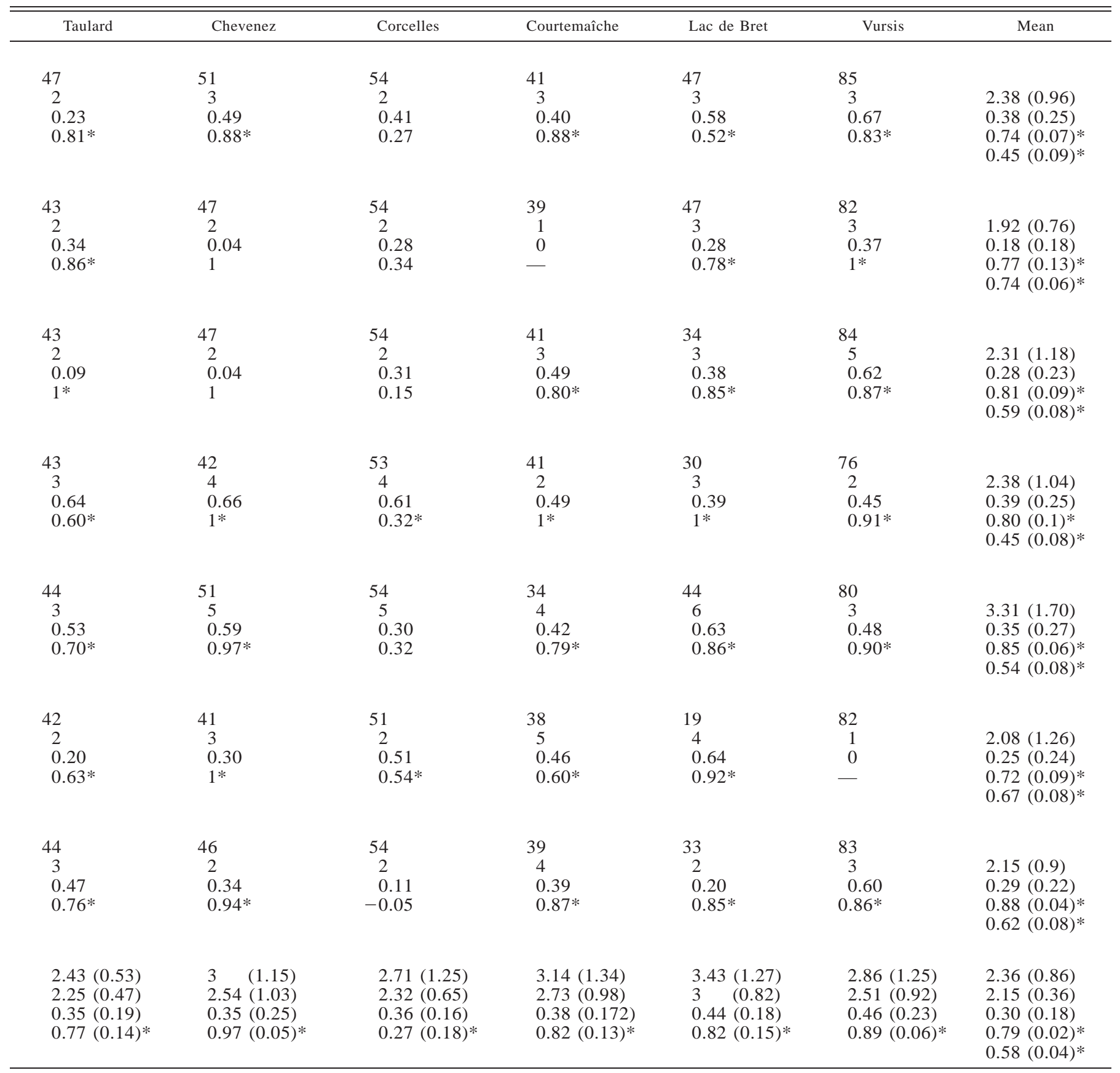

found no genetic variability at six microsatellite loci among 13 sites, separated by $3-240 \mathrm{~km}$ in the northern Bolivian Altiplano.

In the absence of gene flow, genetic drift can lead to reduced genetic variability in populations of limited size (Slatkin 1985). Alternatively, high selfing rates could also account for low variability. It is widely believed that inbreeders present lower levels of within-population genetic variations than outbreeders due to reduced effective population size (Pollak 1987; Jarne 1995), hitchhiking (Hedrick 1980; Kaplan et al. 1989; Berry et al. 1991), and background selection (Charlesworth et al. 1993). Hitchhiking and background selection are likely to be particularly strong in highly self-fertilizing organisms, in which linkage disequilibrium can be strong (Hedrick 1980). Selfing plants often display reduced within population genetic diversity (review in Hamrick and Godt 
TABLE 3. Population and family selfing rates. They are based on single-locus $\left(s_{\mathrm{s}}\right)$, multilocus $\left(s_{\mathrm{m}}\right)$, and $F_{\mathrm{IS}}$-based estimates. Family selfing rates are given for populations exhibiting some outcrossing. Standard deviations (SD) are obtained from 500 bootstraps. BP, fraction of inbreeding due to biparental inbreeding.

\begin{tabular}{|c|c|c|c|c|c|c|c|}
\hline Population & $\begin{array}{l}\text { Number of } \\
\text { families }\end{array}$ & $\begin{array}{l}\text { Number of } \\
\text { clutches/ } \\
\text { family }\end{array}$ & $\begin{array}{c}\text { Number of } \\
\text { offspring }\end{array}$ & $s_{\mathrm{s}}(\mathrm{SD})$ & $s_{\mathrm{m}}(\mathrm{SD})$ & $\begin{array}{l}s\left(F_{\mathrm{IS}^{-}}\right. \\
\text {based })\end{array}$ & $\mathrm{BP}$ \\
\hline Fontenais & 5 & & 37 & $1 \quad(0)$ & $(0)$ & 0.91 & \\
\hline Suchy & 4 & & 40 & $1 \quad(0)$ & $1 \quad(0)$ & 0.96 & \\
\hline Taulard & 5 & & 44 & $0.81(0.11)$ & $0.77(0.11)$ & 0.87 & -0.002 \\
\hline Fam. 9 & & 2 & 10 & & $1 \quad(0)$ & & \\
\hline Fam. 67 & & 2 & 10 & & $1 \quad(0)$ & & \\
\hline Fam. 111 & & 1 & 9 & & $1 \quad(0)$ & & \\
\hline Chevenez & 4 & & 38 & $0.98(0.01)$ & $0.97(0.03)$ & 0.98 & -0.019 \\
\hline Fam. 21 & & 1 & 10 & & $1 \quad(0)$ & & \\
\hline Fam. 42 & & 1 & 9 & & (0) & & \\
\hline Fam. 83 & & 1 & 10 & & $1 \quad(0)$ & & \\
\hline Fam. 101 & & 1 & 9 & & $0.88(0.12)$ & & \\
\hline Corcelles & 7 & & 23 & $0.56(0.11)$ & $0.46(0.11)$ & 0.42 & 0.255 \\
\hline Fam. 74 & & 1 & 7 & & $(0)$ & & \\
\hline Fam. 104 & & 1 & 4 & & $(0.10)$ & & \\
\hline
\end{tabular}

1990; see also Liu et al. 1998). In freshwater snails, several studies confirm the pattern of reduced neutral genetic variability in selfed compared to outcrossed species (for review Jarne and Städler 1995; see also Coutellec-Vreto et al. 1994; Viard et al. 1997).

\section{Mating System}

Lymnaea truncatula appears to be a predominant selfer, although some variations in selfing rate exist among individuals and between populations. Selfing rates were generally higher than $80 \%$, using either a progeny array analysis or estimates based on $F_{\text {IS }}$. The fact that these two approaches provide similar results indicates that the selfing rate is stable and high.

The sample from Corcelles has a lower selfing rate. This could result from a higher density in this population, as expected on theoretical grounds (Tomlinson 1966; Ghiselin 1969, 1974; Jain 1976; Jarne et al. 1993) and confirmed in various studies on plants (e.g., Van Treuren et al. 1993; He et al. 1998; Franceschinelli and Bawa 2000). However, this explanation appears unlikely because Corcelles had at the time of sampling one of the lowest densities in our sampling area. In this population, not only selfing rates were lower, but biparental inbreeding was also higher. Thus, increased outcrossing may have brought an increase in biparental inbreeding. Such inbreeding could reduce the advantage of outcrossing and thus select against further increases in outcrossing. Besides the particular genetic characteristics of Corcelles, this population also exhibits a smaller clutch size of one to three individuals versus five to 10 in the other populations. This could reflect a smaller snail size, a sensitivity of Corcelles snails to laboratory conditions, or early inbreeding depression. We have no evidence for or against the first two hypotheses. Stronger early inbreeding depression in the Corcelles population would indicate among-population differences in inbreeding depression, as reported in several studies (e.g., He et al. 1998; see for review Byers and Waller 1999) and might be related to differences in selfing rate as shown experimentally by Holtsford and Ellstrand (1990) in Clarkia tembloriensis.

\section{Inbreeding Depression}

We found no difference in selfing rate estimated on hatchlings and on adults, nor in heterozygosity between infected and healthy snails. This suggests that inbreeding depression is weak in L. truncatula, although experimental work is needed to confirm this. The few empirical works providing accurate estimates of inbreeding depression in freshwater snails are restricted to outcrossers. They pointed out that high outcrossing rates are associated with strong inbreeding depression. This is the case of Bulinus globosus (Jarne et al. 1991), Lymnaea peregra (Coutellec-Vreto et al. 1998), and Physa acuta (Jarne et al. 2000). Information on inbreeding depression in selfers is restricted to the work of Doums et al. (1996) on Bulinus truncatus and Biomphalaria straminea. They found a high survival of selfed progeny, suggesting inbreeding depression is low. In plants, populations and species with a long history of acute inbreeding often show reduced inbreeding depression (references in Jarne and Charlesworth 1993; Keller and Waller 2002), but many exceptions exist (Ågren and Schemske 1993; Byers and Waller 1999).

The commonly accepted hypothesis for low inbreeding depression in selfers is the purging of deleterious recessive mutations. Indeed, little or no difference in fitness between selfed and outcrossed individuals is expected in large inbred populations, where recessive lethal mutations are exposed to 
selection and eliminated (review in Jarne and Charlesworth 1993). However inbreeding does not necessarily purge the genetic load, particularly if populations are small and mutations are mildly deleterious. In this situation, little inbreeding depression may be expressed because (local) populations may become fixed by genetic drift for some mildly deleterious alleles (Maynard Smith 1978; Keller and Waller 2002). Among-population crosses could determine whether an absence of inbreeding depression results from the local fixation of deleterious mutations. If deleterious recessive alleles are fixed within populations, offspring from among-population crosses are expected to show significantly higher fitness compared to offspring issued from selfing or from crosses within populations. This occurs because between-population crosses result in a net masking of their deleterious effects, reflecting the among-population component of inbreeding depression, a phenomenon termed "drift load" by Whitlock et al. (2000; for review see Keller and Waller 2002).

Inbreeding depression constitutes an important factor in the evolution of mating systems. However, one can wonder whether the among-population component of inbreeding depression played a role in the evolution of selfing in $L$. truncatula. In this species, $58 \%$ of the genetic variation $\left(F_{\mathrm{ST}}\right)$ is attributed to genetic differences among populations, implying little genetic exchanges among populations. Indeed, dispersal is so reduced that even close populations remain highly differentiated $\left(F_{\mathrm{ST}}=0.5\right.$ between Bioley 1 and 2 separated by $25 \mathrm{~m}$ ). Thus, even if among-population crosses are fitter, they are so rare that the among-population component of inbreeding depression may play only a minor role in the evolution of selfing in L. truncatula.

Alternatively, one might argue that the absence of evidence of inbreeding depression in this study is due to the low range of inbreeding levels covered. However, 24\% of the genotyped individuals were heterozygous for at least one of the seven loci, and $5 \%$ for at least three of the loci. Although heterozygosity is only a loose indicator of inbreeding when the number of loci is not large (Keller and Waller 2002; Slate and Pemberton 2002), the range observed here indicates that levels of inbreeding do vary substantially in our samples. These results suggest low within-population inbreeding depression in these populations. Alternatively, inbreeding depression could occur at a stage earlier than egg formation, as suggested by the variance in clutch size (Corcelles's clutches are smaller than clutches from other populations) and limited mortality once eggs are formed (the hatching rate was about 95\%). This will need to be confirmed experimentally.

\section{Harshness of the Habitat}

Lymnaea truncatula has little dispersal capability and colonizes temporary habitats, two features for which selfing constitutes certainly a major advantage. The temporary habitats are frequently subjected to harsh periods of drought inducing demographic bottlenecks (Kendall 1949; Roberts 1950). When conditions became favorable the density is low, thus reducing the probability of finding a mate. In such circumstances, selfing constitutes a reproductive assurance that might have been selected in temporary habitats (Pannell and
Barrett 1998; but see Pannell and Barrett 2001). However, higher selfing rates were not detected in temporary habitats. Nevertheless, we showed that populations from temporary habitats maintain less allelic richness and gene diversity than populations from permanent ones. In a tropical self-fertilizing snail, Bulinus truncatus, Viard et al. (1997) also found reduced polymorphism in populations subjected to variation in population size. The low polymorphism observed in L. truncatula results from the combined effect of the harshness of the habitat and selfing. The first factor should have a stronger effect than selfing because even self-fertilization maintains, at most, half the effective population size (Pollak 1987).

Populations of snails occupying temporary habitats also exhibit a globally higher, albeit nonsignificantly so, $F_{\mathrm{ST}^{-}}$-value. The lack of significance for the $F_{\mathrm{ST}}$-values certainly results from the small number of populations in each group (five permanent and eight temporary populations). Indeed if we replicate each population of our dataset and perform the same analysis, temporary populations appear significantly more differentiated than permanent ones $(P=0.02)$. The higher differentiation of nonpermanent habitats can be explained by fluctuations in population size, which strongly reduce the effective size, amplifying the effect of genetic drift. However, higher differentiation of temporary populations might not be predicted if a large number of founders are involved in recolonization (Wade and McCauley 1988; Whitlock and McCauley 1990). The low levels of amongpopulation gene flow found in L. truncatula suggest that few colonizers found new populations.

\section{Parasitism}

We observed no relationship between selfing rate and the prevalence of infection among the studied populations. Contrary to classical models that predict the evolution of sex when antagonistic coevolution between hosts and parasites occurs (Van Valen 1973; Jaenike 1978; Hamilton et al. 1990), even highly parasitized populations exhibit high selfing rates. However, uniparental reproduction might also constitute an unbeatable strategy in the struggle against parasites. In a metapopulation model, Ladle et al. (1993) predicted that sexuality is far from universally successful. Where there is a large discrepancy between host and parasite migration rates, sex fails and asexuality is favored. Additionally, Lively and Howard (1994) showed that a mixed mating system can be evolutionary stable when parasites exert moderate to severe effects and when the inbreeding depression is less than 0.5. Finally, Agrawal and Lively (2001) pointed out that a mixed mating system, strongly biased toward selfing, appears more successful for a large fraction of the parameter space they investigated, which included several host-parasite genetic interactions (e.g., matching-alleles model and inverse matching-allele model), parasite selfing rate, parasite virulence, and pollen discounting. To evaluate the predictions of these models in snail-digenetic parasite systems requires more empirical work and information on the precise host-parasite genetic interactions.

Within populations, we found no difference in levels of homozygosity between parasitized and healthy individuals. In contrast, Coltman et al. (1999) reported a higher suscep- 
tibility to infection of inbred Soay sheep, which induces a higher mortality during harsh winters. Similarly Meagher (1999) and Cassinello et al. (2001) observed higher rates of infection in inbred deer mice and endangered gazelles, respectively. These researches strongly suggest that in mammals, by removing more homozygous individuals, parasites counter-select inbred genotypes and could select for altered pattern of mating. The discrepancy between these studies and ours might be because we considered a hermaphrodite that mostly self-fertilizes. Deleterious alleles might have been purged or fixed within populations, reducing the (local) inbreeding depression. Alternatively the absence of evidence of different level of homozygosity in infected and healthy snails could result from the fact that heterozygosity might not be a very accurate indicator of inbreeding, as mentioned previously. Finally, a third hypothesis could be that ecology (i.e., the probability of encounter between host and infecting parasites) is more important than genetics in determining patterns of infection.

\section{Conclusion}

Lymnaea truncatula presents a self-fertilization syndrome, as defined by Doums et al. (1996), including a high selfing rate, limited inbreeding depression, and low neutral variability. This syndrome seems to be enhanced by the harshness of the habitat colonized. In temporary habitats, genetic polymorphism is also reduced.

An intriguing question remains: Why does some outcrossing occur given the lack of costs associated with selfing? A simple rule predicts that, due to the cost of outcrossing (Fisher 1941), a mutation that increases the selfing rate is expected to spread in a population if the inbreeding depression is less than 0.5. However, in L. truncatula some individuals still engage in cross-fertilization. Outcrossing seems indeed to be concentrated in a few families. In the 25 families (with more than four offspring), only three contained eggs produced by outcrossing, and only one of the three contained more than one outcrossed egg. Perhaps the trait is not advantageous enough to spread in the population (inbreeding depression is low), yet sufficiently beneficial in some situations (e.g., Corcelles) to be maintained at a low frequency in the metapopulation. For instance, limited sex in hosts (0.05-0.10 of outcrossing) can be an evolutionarily stable strategy when parasites self to some degree and interactions between host and parasite follow a matching allele model (Agrawal and Lively 2001). Alternatively, population dynamics could prevent alleles for self-fertilization from becoming fixed. Indeed, the probability of fixation of selfing is reduced in a metapopulation when the number of immigrants per generation is low and, to a lesser extant, when the probability of extinction is high (Pannell and Barrett 2001). Thus, factors such as inbreeding depression, parasitism, and population dynamics all appear to play a role in maintaining L. truncatula high selfing rate. Further experimental and empirical work is needed to quantify the relative importance of these factors.

\section{ACKNOWLEDGMENTS}

We thank C. Bouteiller, V. Castella, and N. Di Marco for technical assistance and M. Chapuisat, P. Jarne, J. Jokela, L.
Keller, N. Perrin, E. Petit, and M. Reuter for comments on the manuscript. We are especially grateful to D. Waller and two anonymous reviewers for comments that greatly improve the manuscript. This work was supported by a Swiss National Science Foundation grant (31-068325.02) to JG and ST, the Swiss Société Vaudoise des Sciences Naturelles, and the French Embassy in Switzerland (French Ministry des affaires étrangères). LD was supported by Swiss National Science Foundation grant $31-43443.95$ to JG and to Nicolas Perrin. The Fondation Singer-Polignac provided a grant to ST.

\section{Literature Cited}

Agrawal, A. F., and C. M. Lively. 2001. Parasites and the evolution of self-fertilization. Evolution 55:869-879.

Ågren, J., and D. W. Schemske. 1993. Outcrossing rate and inbreeding depression in two annual monoecious herbs, Begonia hirsuta and Begonia semiovata. Evolution 47:125-135.

Ayala, F. J. 1998. Is sex better? Parasites say "'no." Proc. Natl. Acad. Sci. USA 95:3346-3348.

Berry, A. J., J. W. Ajioka, and M. Kreitman. 1991. Lack of polymorphism on the Drosophila fourth chromosome resulting from selection. Genetics 129:1111-1118.

Bilton, D. T., J. R. Freeland, and B. Okamura. 2001. Dispersal in freshwater invertebrates. Annu. Rev. Ecol. Syst. 32:159-181.

Bishop, J. D. D., and J. S. Ryland. 1993. Enzyme electrophoretic evidence for the prevalence of outcrossing in the hermaphroditic brooding ascidian Dendrodoa grossularia (Chordata, Urochordata). J. Exp. Mar. Biol. Ecol. 168:149-165.

Boag, D. A. 1986. Dispersal in pond snails: potential role of waterfowl. Can. J. Zool. 64:904-909.

Bonnell, M. L., and R. K. Selander. 1974. Elephant seals: genetic variation and near extinction. Science 184:908-909.

Byers, D. L., and D. M. Waller. 1999. Do plant populations purge their genetic load? Effects of population size and mating history on inbreeding depression. Annu. Rev. Ecol. Syst. 30:479-513.

Cassinello, J., M. Gomendio, and E. R. S. Roldan. 2001. Relationship between coefficient of inbreeding and parasite burden in endangered gazelles. Conserv. Biol. 15:1171-1174.

Charlesworth, B. 1980. The cost of sex in relation to mating system. J. Theor. Biol. 84:655-671.

Charlesworth, B., and D. Charlesworth. 1999. The genetic basis of inbreeding depression. Genet. Res. 74:329-340.

Charlesworth, B., M. T. Morgan, and D. Charlesworth. 1993. The effect of deleterious mutations on neutral molecular variation. Genetics 134:1289-1303.

Charlesworth, D., and B. Charlesworth. 1987. Inbreeding depression and its evolutionary consequences. Annu. Rev. Ecol. Syst. 18:237-268.

1990. Inbreeding depression with heterozygote advantage and its effect on selection for modifiers changing the outcrossing rate. Evolution 44:870-888.

Cohen, C. S. 1996. The effects of contrasting modes of fertilization on levels of inbreeding in the marine invertebrate genus Corella. Evolution 50:1896-1907.

Coltman, D. W., J. G. Pilkington, J. A. Smith, and J. M. Pemberton. 1999. Parasite-mediated selection against inbred Soay sheep in a free-living, island population. Evolution 53:1259-1267.

Coutellec-Vreto, M. A., A. Guiller, and J. Daguzan. 1994. Allozyme variation in some populations of the freshwater snails Lymnaea peregra, L. auricularia and L. stagnalis (Gastropoda: Pulmonata). J. Molluscan Stud. 60:393-403.

Coutellec-Vreto, M. A., L. Madec, and A. Guiller. 1997. Selfing and biparental inbreeding: a mating system analysis in Lymnaea peregra (Gastropoda: Lymnaeidae). Heredity 79:277-285.

Coutellec-Vreto, M.-A., P. Jarne, A. Guiller, L. Madec, and J. Daguzan. 1998. Inbreeding and fitness in the freshwater snail Lymnaea peregra: an evaluation over two generations of self-fertilization. Evolution 52:1635-1647.

Crow, J. F. 1999a. Dominance and overdominance. Pp. 49-58 in J. G. Coors and S. Pandey, eds. Genetics and exploitation of 
heterosis in crops. American Soceity of Agronomy, Madison, WI.

1999b. The rise and fall of overdominance. Plant Breed. Rev. 17:225-257.

Darwin, C. 1876. The effects of cross and self-fertilization in the vegetable kingdom. J. Murray, London.

Dillon, R. T., Jr. 2000. The ecology of freshwater molluscs. Cambridge Univ. Press, Cambridge, U.K.

Doums, C., F. Viard, A.-F. Pernot, B. Delay, and P. Jarne. 1996. Inbreeding depression, neutral polymorphism, and copulatory behavior in freshwater snails: a self-fertilization syndrome. Evolution 50:1908-1918.

El Mousadik, A., and R. J. Petit. 1996. High level of genetic differentiation for allelic richness among populations of the argan tree [Argania spinosa (L.) Skeels] endemic to Morocco. Theor. Appl. Genet. 92:832-839.

Fisher, R. A. 1941. Average excess and average effect of a gene substitution. Ann. Eugen. 11:53-63.

Flor, H. H. 1956. The complementary genetic system in flax and flax rust. Adv. Genet. 8:29-54.

Franceschinelli, E. V., and K. S. Bawa. 2000. The effect of ecological factors on the mating system of a South American shrub species (Helicteres brevispira). Heredity 84:116-123.

Frank, S. A. 1993. Specificity versus detectable polymorphism in host-parasite genetics. Proc. R. Soc. Lond. B 254:191-197.

- 1994 . Recognition and polymorphism in host-parasite genetics. Philos. Trans. R. Soc. B 346:283-293.

Ghiselin, M. T. 1969. The evolution of hermaphroditism among animals. Q. Rev. Biol. 44:189-208.

- 1 1974. The economy of nature and the evolution of sex. Univ. of California Press, Berkeley, CA.

Giles, B. E., and J. Goudet. 1997. Genetic differentiation in Silene dioica metapopulations: estimation of spatiotemporal effects in a successional plant species. Am. Nat. 149:507-526.

Goudet, J. 2001. FSTAT, a program to estimate and test gene diversities and fixation indices (version 2.9.3). Available via http: //www.unil.ch/izea/softwares/fstat.html.

Goudet, J., M. Raymond, T. De Meeus, and F. Rousset. 1996. Testing differentiation in diploid populations. Genetics 144: 1933-1940.

Hamilton, W. D., R. Axelrod, and R. Tanese. 1990. Sexual reproduction as an adaptation to resist parasites (a review). Proc. Natl. Acad. Sci. USA 87:3566-3573.

Hamrick, J. L., and M. J. Godt. 1990. Allozyme diversity in plant species. Pp. 43-63 in A. H. D. Brown, M. T. Clegg, A. L. Kahler, and B. S. Weir, eds. Plant population genetics, breeding and genetic resources. Sinauer Associates, Sunderland, MA.

Hartl, D. L., and A. G. Clark. 1997. Principles of population genetics. Sinauer Associates, Sunderland, MA.

He, T. H., G. Y. Rao, R. L. You, and S. Ge. 1998. Mating system of Ophiopogon xylorrhizus (Liliaceae), an endangered species in southwest China. Int. J. Plant Sci. 159:440-445.

Hedrick, P. W. 1980. Hitchhiking: a comparison of linkage and partial selfing. Genetics. 94:791-808.

Herlihy, C. R., and C. G. Eckert. 2002. Genetic cost of reproductive assurance in a self-fertilizing plant. Nature 416:320-323.

Holtsford, T. P., and N. C. Ellstrand. 1990. Inbreeding effects in Clarkia tembloriensis (Onagraceae) populations with different natural outcrossing rates. Evolution 44:2031-2046.

Hurst, L. D., and J. R. Peck. 1996. Recent advances in understanding of the evolution and maintenance of sex. Trends Ecol. Evol. 11: $46-52$.

Jaenike, J. 1978. An hypothesis to account for the maintenance of sex within populations. Evol. Theor. 3:191-194.

Jain, S. K. 1976. The evolution of inbreeding in plants. Annu. Rev. Ecol. Syst. 7:469-495.

Jarne, P. 1995. Mating system, bottlenecks and genetic polymorphism in hermaphroditic animals. Genet. Res. 65:193-207.

Jarne, P., and D. Charlesworth. 1993. The evolution of the selfing rate in functionally hermaphrodite plants and animals. Annu. Rev. Ecol. Syst. 24:441-466.

Jarne, P., and B. Delay. 1990. Inbreeding depression and self-fer- tilization in Lymnaea peregra (Gastropoda: Pulmonata). Heredity $64: 169-175$.

Jarne, P., and P. J. L. Lagoda. 1996. Microsatellites, from molecules to populations and back. Trends Ecol Evol. 11:424-429.

Jarne, P., and T. Städler. 1995. Population genetic structure and mating system evolution in freshwater pulmonates. Experientia 51:482-497.

Jarne, P., and A. Théron. 2001. Genetic structure in natural populations of flukes and snails: a practical approach and review. Parasitology 123:S27-S40.

Jarne, P., L. Finot, B. Delay, and L. Thaler. 1991. Self-fertilization versus cross-fertilization in the hermaphroditic freshwater snail Bulinus globosus. Evolution 45:1136-1146.

Jarne, P., M. Vianey-Liaud, and B. Delay. 1993. Selfing and outcrossing in hermaphrodite freshwater gastropods (Basommatophora): where, when and why. Biol. J. Linn. Soc. 49:99-125.

Jarne, P., M.-A. Perdieu, A.-F. Pernot, B. Delay, and P. David. 2000. The influence of self-fertilization and grouping on fitness attributes in the freshwater snail Physa acuta: population and individual inbreeding depression. J. Evol. Biol. 13:645-655.

Jokela, J., C. M. Lively, M. F. Dybdahl, and J. A. Fox. 1997. Evidence for a cost of sex in the freshwater snail Potamopyrgus antipodarum. Ecology 78:452-460.

Kaplan, N. L., R. R. Hudson, and C. H. Langley. 1989. The hitchhiking effect revisited. Genetics 123:887-899.

Keller, L. F., and D. M. Waller. 2002. Inbreeding effects in wild populations. Trends Ecol. Evol. 17:230-241.

Kendall, S. B. 1949. Bionomics of Limnaea truncatula and the parthenitae of Fasciola hepatica under drought conditions. J. Helminth. 23:57-68.

- 1953. The life-history of Limnaea truncatula under laboratory conditions. J. Helminth. 27:17-28.

Kirkpatrick, M., and P. Jarne. 2000. The effects of a bottleneck on inbreeding depression and the genetic load. Am. Nat. 155: $154-167$.

Ladle, R. J., R. A. Johnstone, and O. P. Judson. 1993. Coevolutionary dynamics of sex in a metapopulation: escaping the Red Queen. Proc. R. Soc. Lond. B 253:155-160.

Lande, R., and D. W. Schemske. 1985. The evolution of self-fertilization and inbreeding depression in plants. I. Genetic models. Evolution 39:24-40.

Leberg, P. 1992. Effects of population bottlenecks on genetic diversity as measured by allozyme electrophoresis. Evolution 46: 477-494.

Liu, F., L. Zhang, and D. Charlesworth. 1998. Genetic diversity in Leavenworthia populations with different inbreeding levels. Proc. R. Soc. Lond. B 265:293-301.

Lively, C. M., and R. S. Howard. 1994. Selection by parasites for clonal diversity and mixed mating. Phil. Trans. R. Soc. Lond. B 346:271-281

Malek, E. A. 1980. Snail-transmitted diseases. Vol. I and II. CRC Press, Inc., Boca Raton, FL.

Malone, C. R. 1965. Killdeer (Charadrius vociferus Linnaeus) as a means of dispersal for aquatic gastropods. Ecology 46:551-552.

Manly, B. F. J. 1997. Randomization, bootstrap and Monte Carlo methods in biology. 2d ed. Chapman and Hall, London.

Maynard Smith, J. 1978. The evolution of sex. Cambridge Univ. Press, Cambridge, U.K.

Meagher, S. 1999. Genetic diversity and Capillaria hepatica (Nematoda) prevalence in Michigan deer mouse populations. Evolution 53:1318-1324.

Meunier, C., C. Tirard, S. Hurtrez-Bousses, P. Durand, M. D. Bargues, S. Mas-Coma, J. P. Pointier, J. Jourdane, and F. Renaud. 2001. Lack of molluscan host diversity and the transmission of an emerging parasitic disease in Bolivia. Mol. Ecol. 10: $1333-1340$.

Nei, M. 1987. Molecular evolutionary genetics. Columbia Univ. Press, New York.

Nei, M., T. Maruyama, and R. Chakraborty. 1975. The bottleneck effect and genetic variability in populations. Evolution 29:1-10.

Otto, S. P., and Y. Michalakis. 1998. The evolution of recombination in changing environments. Trends Ecol. Evol. 13: $145-151$ 
Pannell, J. R., and S. C. H. Barrett. 1998. Baker's law revisited: reproductive assurance in a metapopulation. Evolution 52: $657-668$.

- 2 2001. Effects of population size and metapopulation dynamics on a mating-system polymorphism. Theor. Popul. Biol. 59:145-155.

Petit, E., F. Balloux, and J. Goudet. 2001. Sex-biased dispersal in a migratory bat: a characterization using sex-specific demographic parameters. Evolution 55:635-640.

Petit, R. J., A. El Mousadik, and O. Pons. 1998. Identifying populations for conservation on the basis of genetic markers. Conserv. Biol. 12:844-855.

Pollak, E. 1987. On the theory of partially inbreeding finite populations I. Partial selfing. Genetics 117:353-360.

Purchon, R. D. 1968. The biology of the mollusca. Pergamon Press, Oxford, U.K.

Rice, W. R. 1989. Analysing tables of statistical tests. Evolution 43:223-225.

Ritland, K. 1986. Joint maximum likelihood estimation of genetic and mating structure using open-pollinated progenies. Biometrics $42: 25-43$.

1990. Inferences about inbreeding depression based on changes of the inbreeding coefficient. Evolution 44:1230-1241.

Ritland, K., and S. Jain. 1981. A model for the estimation of outcrossing rate and gene frequencies using $n$ independent loci. Heredity 47:35-52.

Roberts, E. W. 1950. Studies on the life-cycle of Fasciola hepatica (Linnaeus) and of its snail host, Limnaea (Galba) truncatula (Müller), in the field and under controlled conditions in the laboratory. Ann. Trop. Med. Parasitol. 44:187-206.

Rondelaud, D., and C. Mage. 1992. Lymnaea truncatula Müller: les consequences d'une seule génération annuelle sur les caractéristiques de l'infestation par Fasciola hepatica. Rev. Méd. Vét. 143:843-846.

Rousset, F. 1997. Genetic differentiation and estimation of gene flow from F-statistics under isolation by distance. Genetics 145 : 1219-1228.

Slate, J., and J. M. Pemberton. 2002. Comparing molecular measures for detecting inbreeding depression. J. Evol. Biol. 15: 20-31.

Slatkin, M. 1977. Gene flow and genetic drift in a species subject to frequent local extinctions. Theor. Popul. Biol. 12:253-262.

- 1985 . Gene flow in natural populations. Annu. Rev. Ecol. Syst. 16:393-430.

Smith, G. 1981. Copulation and oviposition in Lymnaea truncatula (Müller). J. Molluscan Stud. 47:108-111.

Sorensen, R. E., and D. J. Minchella. 1998. Parasite influences on host life history: Echinostoma revolutum parasitism of Lymnaea elodes snails. Oecologia 115:188-195.

Städler, T., and P. Jarne. 1997. Population biology, genetic structure, and mating system parameters in freshwater snails. Pp. 231-262 in B. Streit, T. Städler, C. M. Lively, eds. Evolutionary ecology of freshwater animals. Birkhäuser, Basel.
Tomlinson, J. 1966. The advantages of hermaphroditism and parthenogenesis. J. Theor. Biol. 11:54-58.

Trouvé, S., F. Renaud, P. Durand, and J. Jourdane. 1996. Selfing and outcrossing in a parasitic hermaphrodite helminth (Trematoda, Echinostomatidae). Heredity 77:1-8.

. 1999a. Reproductive and mate choice strategies in the hermaphroditic flatworm Echinostoma caproni. J. Hered. 90: 582-585.

Trouvé, S., J. Jourdane, F. Renaud, P. Durand, and S. Morand. 1999b. Adaptive sex allocation in a simultaneous hermaphrodite. Evolution 53:1599-1604.

Trouvé, S., L. Degen, C. Meunier, C. Tirard, S. Hurtrez-Bousses, P. Durand, J. F. Guégan, J. Goudet, and F. Renaud. 2000. Microsatellites in the hermaphroditic snail, Lymnaea truncatula, intermediate host of the liver fluke, Fasciola hepatica. Mol. Ecol. 9:1662-1664.

Uyenoyama, M. K., K. E. Holsinger, and D. M. Waller. 1993. Ecological and genetic factors directing the evolution of self-fertilization. Oxf. Surv. Evol. Biol. 9:327-381.

Van Treuren, R., R. Bijlsma., N. J. Ouborg, and W. Van Delden. 1993. The effects of population size and plant density on outcrossing rates in locally endangered Salvia pratensis. Evolution 47:1094-1104

Van Valen, L. 1973. A new evolutionary law. Evol. Theor. 1:1-30.

Viard, F., F. Justy, and P. Jarne. 1997. The influence of self-fertilization and population dynamics on the genetic structure of subdivided populations: a case study using microsatellite markers in the freshwater snail Bulinus truncatus. Evolution 51: $1518-1528$.

Victoir, K., and J. C. Dujardin. 2002. How to succeed in parasitic life without sex? Asking Leishmania. Trends Parasitol. 18: $81-85$.

Wade, M. J., and D. E. McCauley. 1988. Extinction and recolonization: their effects on the genetic differentiation of local populations. Evolution 42:995-1005.

Waller, D. M., and S. E. Knight. 1989. Genetic consequences of outcrossing in the cleistogamous annual, Impatiens capensis. II. Outcrossing rates and genotypic correlations. Evolution 43: 860-869.

Weir, B. S., and C. C. Cockerham. 1984. Estimating $F$-statistics for the analysis of population structure. Evolution 38:1358-1370.

Wethington, A. R., and R. T. Dillon Jr. 1991. Sperm storage and evidence for multiple insemination in a natural population of the freshwater snail, Physa. Am. Malacol. Bull. 9:99-102.

Whitlock, M. C., and M. C. McCauley. 1990. Some population genetic consequences of colony formation and extinction: genetic correlations within founding groups. Evolution 44: 1717-1724.

Whitlock, M. C., P. K. Ingvarsson, and T. Hatfield. 2000. Local drift load and the heterosis of interconnected populations. Heredity 84:452-457.

Wright, S. 1969. Evolution and the genetics of populations: the theory of gene frequencies. Vol. 2. Univ. of Chicago Press, Chicago, IL.

Corresponding Editor: D. Waller 